\title{
The Choice of English Forms and Pragmatic Motivation---- Taking Propose as an Example
}

\author{
WU Guoliang* \\ Zhejiang Yuexiu University of Foreign Languages \\ *Corresponding Authors: WU Guoliang,Zhejiang Yuexiu University of Foreign Languages

\begin{abstract}
In the English language and literature, people often meet with problems of a choice of some sentence patterns. As we know, on many occasions one certain content can be expressed in several different forms. There might exist different translations for the same sentence as well. Of course, the best form should first satisfy the criterion of "pragmatic equivalence". This paper, taking propose as an example, is to give an in-depth description of the use and meaning of propose, including potential semantic meaning, historical development, the form and function, syntax and pragmatics, and their related translations, concentrating on the pragmatic motivation. This paper applies the insights of cognitive linguistics to lexical choice, focusing on the choice in conformity with "the right word at the right time. Meanwhile this paper reinforces the view point that the traditional analysis of the grammatical variation should be associated with multidimensional methodology.
\end{abstract}

Keywords:propose; potential meaning; choice of form; pragmatic motivation

\section{INTRODUCTION}

The Linguist Borkin (1984:81) makes a comment on the three sentences with the same content:

(1) I find that this chair is uncomfortable.

(2) I find this chair to be uncomfortable.

(3) I find this chair uncomfortable.

As we know, there are no grammatical mistakes in the above three sentences, with the same subject and predicate followed by three types of complement clauses whose contents are basically the same . The contexts which they are in, however, are different.

Borkin (1984: 79) 's following description provides a possible context: The trio of sentences with find in (1-3) can be viewed from this angle as well; the complement in (1), then, represents a proposition viewed as based on evidence, while the complement in (3) represents the report of an experience. I might use (1) but not (3) as a statement about consumer reaction tests, but I would use (3) and not (1) as a statement about how the chair feels to me., (2), on the other hand, might be used in either circumstance.

To say it in a more specific way, the degree of the directness of the evidence for the proposition in the three sentences is different. WANG (2001:44) points out: Any choice is meaningful from the view point of functional linguistics. The notion "Choice is meaning" is a principle that can be applied widely. We are making choices all the time, and each choice is usually meaningful. Even if sometimes the choice is made without being conscious. This choice, however, is still meaningful. From the perspective of discourse analysis, form is the realization of meaning (WANG 1999: 106-115)

Please see the following two sentences with the main verbs being believe:

(4)I believe that he is honest.

(5) I believe him to be honest.

Verspoor (1990:43) points out: [I believe him to be honest] is used when there is some direct evidence for the belief, and therefore expresses a stronger degree of commitment to the truth of the proposition expressed in the complement than [I believe that he is honest].

International Journal on Studies in English Language and Literature (IJSELL)Page | 30 
Here it contains the pragmatic motivation of the choice of patterns in the related translation. Just as Matsumoto (2008: 132) points out : Within the functional and the cognitive paradigm, it is generally accepted that if one verb can be followed by more than one type of complement, there must be semantic differences among the sentences with different pragmatic effects.

So it's clear that applying the linguistic theory to the translation practice can raise the related translation to the level of reason. The reason for this paper to take propose as an example is that the word propose is typical in terms of language.

Oxford Word power Dictionary for Learners of English (Steel, 2000: 526) provides a clear and simple paraphrase for Propose: the first two points are:

Verb $1[\mathrm{~T}]$ to formally suggest sth as a possible plan or action: At the meeting a new advertising campaign was proposed.2 [T] to intend to do sth; to have sth as a plan: What do you propose to do now?

This shows that the basic meaning of propose has something to do with suggest and intend. The paraphrases, however, fail to give a complete picture because of being too simple. The problem is that the potential differences between them are seldom mentioned in ordinary lexical books. In fact, these three words have similarities with, and differences to, each other. Each has its own features in semantics. In terms of pragmatics, apart from the differences in stylistics, there are still plenty of contents which are worth taking an in-depth study.

\section{FUndaMental MeANingS}

Sinclair (1997:506) gives a clear and simple description for propose:

1 VERB if you propose a plan or idea, you suggest it. Britain is about to propose changes to European community institutions. 2 VERB if you propose to do something, you intend to do it. It's still far from clear what action the government proposes to take...And where do you propose building such a huge thing? 3 VERB If you propose to someone, you ask them to marry you.

In Macquarie Learners Dictionary (Atkinson, 1999: 620), under the first two definitions of the entry propose, there is one example for each item: verb 1. Rather formal to put forward or suggest: I propose that we all go for a walk. 2. Rather formal to plan or intend: The council proposes to paint the library building.

The dictionary holds that for the paraphrase 1, the more commonly used word is suggest; and for paraphrase2, the more commonly used word is intend. These are their interchangeable points. Then what are the differences between propose and suggest? Is the difference of styles, whether formal or informal, the only difference there is between them? Let's first see the description of the use of suggest and propose, under the entry of suggestion, given by Thomson\&Martinet (1986: 252) : First, second or third person suggestions with suggest or propose

Suggest (+possessive adjective) +gerund, suggestthat+subject+presenttense/should .

Propose is used in exactly the same way but is slightly more formal than suggest.

In the active, suggest + should +infinitive is more formal than suggest $+a$ present or past tense.

In fact, there are differences in semantics and pragmatics between these forms followed by suggest.

Let's see the lexical meaning of propose and suggest described by Lea,(2008: 595), which shows the subtle difference between the two words: propose [T] (rather formal) to tell people about a plan or idea for them to think about and decide on. Suggest [T] to tell people about a plan or idea for them to think about. Put sty forward phrasal verb (rather formal) to tell people about a plan or idea for them to discuss usually so that sth can be decided: Several suggestions were put forward for possible venues. He put forward some very convincing argument.

From the above paraphrases, we can see propose goes a further step than suggest does and has one more sense"and decide on", whose subtle difference can hardly be observed without comparison.

In addition, there are also other obvious differences between propose and suggest or put forward, mainly involving in whether the discourse context is formal or not, the degree of self confidence of the speaker, and even related to in which person someone occurs. All the things are existing by means 
of comparison. We get a clear impression through a comparison of the three words in Oxford Learner's Thesaurus (Lea, 2008:595): Note PROPOSE, SUGGESTOR PUT FORWARD? Suggest is often used in less formal situations than PROPOSE or PUT FORWARD, especially when making personal suggestions or arrangements:' I suggest that we go out to eat.' You can say 'I propose that we go out to eat, ' but this sounds very formal. Put something forward is NOT used with $I$ in this way:?I put forward that we go out to eat. Suggest is sometimes less certain than propose or put something forward: you might suggest sth in order to be helpful, or in a gentle way because you are not sure how welcome your suggestion will be; you are more likely to propose or put sth forward in a confident way and when you definitely want your idea to be accepted. When sth is to be considered in a formal process it is more usual to use propose or put sth forward: They are ready to discuss plans proposed/put forward by the UN. ?They are ready to discuss plans suggested by the UN. You can put forward but NOT PROPOSE OR SUGGEST a suggestion or argument. Nevertheless, there is an exception. Occasionally,we can still hear such kind of sentence"I put forward that...." The following passage is from BNC:

Absolutely a nil sheet yes, I have no trouble with the referees, in fact at our conference erm when they talked about referees, I put forward that erm there should be a vote of thanks for the referees, because at long last some of them are listening. (BNC KS7)

According to the rhetoric of the sentence, the above passage is obviously in an informal context.

Therefore, compared with suggest, propose is not only more formal in style, but is also more sure in thought, more confident in manner and used when you really want your idea to be accepted. This is also one of the pragmatic motivations of the choice of the two words.

As to the influence of the context on the choice of words, Longman Dictionary of Common Errors (Turton \& Heaton, 1996: 271) provides an enlightening analysis. Though it is a little bit strict, it is, however, reasonable. See the following two examples, one of which is wrong:

(6) *I propose you to talk to John about it.

(7) I suggest that you talk to John about it.

Their explanation is : Propose $=$ formally suggest an idea, plan or course of action, especially to an official person or group that has the power to decide: 'May I propose that we postpone further discussion of this matter until our next meeting.'

This shows that the semantic and pragmatic features are extremely important for the pragmatic translation, especially for non English native speakers. In addition, in terms of English usage, there is a constraint on the use of propose followed by an infinitival complement construction.

Collins COBUILD English Usage (Sinclair, 1999:544) provides a note which is worth mentioning : Note that you do not use a 'to' -infinitive in sentences like these. You do not say, for example, 'The staff association proposed a mediator to be nominated'

In fact, Sentence (6) has also an error in syntax. See the common mistakes pointed out by Longman Exams Dictionary (Bullon, 2011:1883) : *Propose sb to do sth

Suggest that $\mathrm{sb}$ (should) do sth she suggested that I try applying for a grant.

In this respect, it is the same as the feature of suggest. See the sentence comparison in

Longman Dictionary of Common Errors (Turton \& Heaton, 1996: 315) :

(8)*I suggest you to take more exercise.

(9)I suggest (that) you take more exercise.

Suggest (that) sb (should) do sth: 'I suggest you try the chemist's in the high street. 'The chairman suggested that the two sides should meet again the following day.'

The famous linguist Swan (1980: 505) also regards this pattern "propose somebody to do something" as a typical mistake: *I proposed her to come with me.

Their explanation is : Propose cannot be used with the structure object +infinitive. 
We find, however, that such kind of pattern can be found occasionally in the written materials of UK and USA, especially when somebody is a reflexive pronoun. The following passage is from BNC:

After mature deliberation your Committee venture to propose to you to entrust them with powers to digest a scheme for the medical department, to receive claims, and investigate the merits of the different candidates who may propose themselves to fill the different situations in the line, as well as of the subordinate attendants of the house, and to report to you at your next general meeting the names of such persons as to them appear most proper, for your final approbation.' (CMG 1181) (Egan 382)

This is,however, only one of individual examples which cannot be a strong evidence. It is not suitable to follow, especially not suitable for non English native speakers to follow.

Why can't we use the pattern propose somebody to do something? It is very difficult to find an answer in an ordinary lexical book. The traditional English usually regards it as an habitual usage. However, as the development of the semantic study, people find that the syntactic constraint on the use of suggest and propose is fundamentally related to the potential meaning of them. Suggest is a mild,tentative, modest speech act.

Wierzbicka(1987:187) has a semantic description of suggest, which is quite helpful for us to make a deep study of it : "The only invariant reason for making a suggestion is the one specified in the explication: The speaker wants the addressee to consider whether he would want to do what the speaker puts forward as a possibility to think about. For this reason, suggest is a mild,tentative, unassuming speech act. The speaker is not attempting to influence the addressee--he is merely trying to assist him in making his own decision by drawing his attention to some possibilities which he might have overlooked.

As to why does suggest give people a sense of tentativeness, Wierzbicka (1987:187) has another convincing description: Common utterances with disclaimers such as "it's just a suggestion"highlight the tentativeness of the speaker's attitude and suggest the component 'I don't want to say that I want you to do it'. This tentativeness of suggesting is reflected in the syntax: one can ask, order, or advise someone to do something, but one cannot suggest someone to do something, as one cannot propose or recommend someone to do something (cf."John asked Mary to do it" vs." * John suggested Mary to do it").

That is to say, the noun phrase referring to addressee cannot be put in the place of object. People can propose or recommend something to someone, and people can suggest something to someone-- -All tentative speech act does not mean to directly or indirectly influence the addressee. Although propose is simlilar to suggest in quite a few respects, there are , however, some subtle points in pragmatics ,which are noteworthy. Just as Wierzbicka (1987:188) points out: In some respects, propose is similar to suggest, which also implies that the speaker is in favour of an action and that he wants the addressee to consider this action to see if he, too, would be in favour of it. But in the case of suggest the speaker's support for the action is more tentative ('I think it might be good if...'); the action doesn't have to be collective and it doesn't have to involve the speaker ('I think it might be good if you did X'); and the addressee doesn't have to say whether or not he accepts the suggestion, (so that the component 'I assume that you will say it', which is necessary for propose, is not necessary for suggest).

We hold that to deal with these subtle differences, English native speakers will make a precise choice of the related words based on different language contexts. For the non- English native speakers, however, they need to make an in-depth study before they reach the level of making a precise choice of words in related translation. The base of such choice is pragmatic motivation.

Propose has quite a few constraints that will be easily ignored, which is mainly caused by the influence of the usage of synonyms. For example, don't say 'propose someone something'. Say propose something. (Longman Dictionary of Contemporary English $\left(5^{\text {th }}\right.$ edition)) Why does the dictionary specially point it out? I think it is because quite a few English learners are familiar with the use of offer and the like : offer somebody something: He offered her a seat, then buzzed for a clerk.(Herbst 2004: 564)

In fact, there is a reason for this phenomenon. In the final analysis it is related with the function of the structure and its potential meaning. See the description of the contrast between right and wrong by 
Wierzbicka (1988:383) : ...On the other hand,verbs such as propose and suggest, which can often be used interchangeably with offer, are normally used with an external dative only (and most commonly are used without any $\mathrm{T}$ phrase whatsoever):

(10)*John proposed Mary a cup of tee.

(11)*John suggested Mary a cup of tee.

(12)John proposed/suggested a cup of tee.

No doubt this is due to the fact that propose and suggest don't imply any specifiable effect on T ( if A proposes or suggests $a \mathrm{P}$ to $\mathrm{T}$ this doesn't imply that $\mathrm{T}$ can have that $\mathrm{P}$ because of that, as is the case with offering).

For the above symbols, Wierzbicka(1988:376) has an explanation:With speech act verbs, A (Agent) stands for the speaker, $\mathrm{T}$ (Target) stands for the addressee, and P (Patient)

Stands either for the speech itself or for some correlate to the speech (its content or its referent).

We can also find other similar examples of synonyms of propose :

(13)? I recommend you this wine. (Wierzbicka, 1988:384)

In terms of traditional English grammar, Propose and suggest usually are not followed by double object.

(14)There are also examples of the contrast between right and wrong from Longman Dictionary of Common Errors (Turton\&Heaton, 1996:271) :

$(15)^{*}$ A friend of mine has proposed me a job in his restaurant.

(16)A friend of mine has offered me a job in the restaurant.

Now let's give a further explanation of the relevance of semantics to syntax.

Swan (1980:505) points out : In the sense of intend, propose can be followed by an infinitive. I propose to have lunch now. (=I'm going to have lunch now.)

The commonly used patterns of propose are: propose to do something; propose doing something; propose +that clause.

It is meaningful for English learners to make a distinction between these patterns in terms of semantics and pragmatics.In practical English, however,even some dictionaries don't pay attention to such kind of distinction.See the examples from The New Sunrise English-Chinese Dictionary by Song Meihua\& Chen Changfang (2001:1593), who regard the first two patterns as equal:

[propose+doing/propose+ to do] He proposed (our) leaving now. = He proposed to leave now.

[propose + to do/propose + doing ( intend to do) We propose to eat out tonight.=We propose eating out tonight.

[propose+that] I proposed that we (should) take a trip to Hawaii. = I proposed (our) taking a trip to Hawaii.

We hold that the two sides of the equations are not really equal. It is generally believed that there is no obvious difference between the pattern propose + infinitive and the pattern propose + ing form .If there is any subtle difference, it has something to do with the fact that different structure has different function.

Egan (2008:381) provides the evidence of frequency of the three patterns from BNC:

\begin{tabular}{|l|c|l|l|l|l|l|l|}
\cline { 3 - 8 } \multicolumn{1}{c|}{} & \multirow{2}{*}{ BNC } & \multicolumn{3}{c|}{ Same-subject } & \multicolumn{3}{c|}{ Different-subject } \\
\cline { 3 - 8 } & & to inf. & bare inf. & -ing & to inf. & bare inf. & -ing \\
\hline propose & 7511 & $* * * * *$ & & $* * *$ & $* *$ & & \\
\hline
\end{tabular}

Propose occurs in three Forward-looking Communication Constructions. 
We hold that the data reflected by frequency statistics are also a kind of pragmatic motivation: The usage tendency of the patterns. The choice of the patterns, andsemantics, however, are usually interwoven with each other.

The following description adds the semantic content to the usage tendency.

: Propose meaning 'intend' usually takes the infinitive:

(17)I propose to start tomorrow.

Propose meaning 'suggest' takes the gerund:

(18)I propose waiting till the police get here.

Palmer (1968: 166) points out:

There are a few verbs that are used to refer to a single action in the future, notably INTEND, PLAN,PROPOSE : (19) I intend going/to go tomorrow.

(20)I plan going/to go tomorrow.

There is no obvious difference in meaning between the alternatives. Generally, of course, the infinitive, structure 2 , is used to refer to a single action in the future.

In fact, this view point is in conformity with that of Wood (1956:13) : The gerund denotes something more general, the infinitive something more specific. Contrast $I$ don't like writing to the papers (expressions of a general dislike)and I don't like to write to the papers (on a particular occasion or subject).

Their explanation of the difference between the infinitive and ing form mutually verifies. Here both propose to do somethingand propose doing something refer to the future things. This is the special uses for propose and dozens of others. The difference in different lexical groups, however, are not the same.

Herbst (2004:623) has a concise and comprehensive description: Bpropose can mean 'suggest'. A person can propose

- something to someone

- To do or doing something. Note that propose doing can mean 'plan' rather than 'suggest' if the carrying out of the action is the sole decision of the person proposing.

- That something should be done.

The second item above tells us that propose doing can refer to 'plan' rather than 'suggestion', if the performance of the action is only the decision of the person who makes the plan. In this respect, its pragmatic feature and the feature of intend doing described by Eagan(2008:248) can be verified mutually. It is typical of the 'intend -ing' construction that it encodes situations which are completely up to the subject to bring about. Both the description come from the corpus study.

It is worth noting that propose in propose to do something can mean 'intend'. As a matter of fact, the use of propose has also a process changing. Freeman (1990:213)has a description about it: At one time the word meaning intend was purpose; propose was considered a misusage. Nowadays one may use either word for that sense; in fact propose has come into wider usage. One may say, since both propose and purpose mean to intend or to plan, "I purpose to continue with his plan" or "I propose to continue with his plan."

In the second paraphrase of the entry propose,Sinclair (1997:507) clearly points out : 2 VERB If you propose to do something, you intend to do it. It's still far from clear what action the government proposes to take...

Intend to do something and intend doing something they are different in pragmatics. Just as Eagan (2008:248)points out: 'Intend to infinitive' typically profiles an intention on the part of the subject to proceed towards a goal that may or may not be reachable; 'intend -ing'typically profiles an intention to realize a situation without even raising the possibility that it may not be realizable. 
It follows that the two structures are different in connotation. In addition, there is another lexical meaning that can easily be ignored. As Herst (2004:623) points out:Propose can mean 'claim'. A scientist or philosopher can propose

\section{(1) A theory}

\section{(2) That something is the case.}

The Report proposed that local authorities, together with the police, should be given a clear statutory responsibility for crime prevention in the area. He would be proposing that they hold joint peace rallies in areas affected by violence. (Herbst, 2004:622)

For non-English native speakers, the above use of propose is worth paying attention to, because the translation of the word claim will vary based on different contexts. This occurs most often in the academic expressions. For example: I propose that the complementizer that, in addition to imposing an atemporal ( and possibly nominal) construal on the clause it combines with, serves to objectify the conception of the proposition expressed. ( Langacker, 1991: 447 )

Furthermore, there is another semantic feature which is different from those of other synonyms. The person who proposes something, envisages a collective action, etc as pointed out by Wierzbicka(1987: 188): Theperson who proposessomething (a toast, an armistice, new legislation or whatever) envisages a collective action, including both the speaker and the addressee. The speaker himself is in favor of this collective action, but he knows that he cannot cause it to take place unless the other people involved also express themselves in its favour. What he wants to achieve, therefore, is to make those other people consider this action and to say whether they want it to happen.

Meanwhile,in a dictionary,sometimes there is a phenomenon that two patterns are combined in one item with the same paraphrase, which seems to mean that the two forms are very close in meaning.For example, in the Longman Dictionary of English Language and Culture (Run dell, 2004:1399) : [+ving/that] I propose delaying our decision until next meeting/ that we delay our decision until the next meeting.

We hold that as a matter of fact there are still some semantic differences between the two patterns. The reason for the combination is that they are extremely close in meaning.This idea can be verified through the following passage given by Dixon (2016:241) : For many verbs THAT and ING complements show considerable overlap in meaning and use. But there is always an implicit - or potential — semantic contrast, along the lines we have described. Consider propose, in

(21a)I propose (our) walking from John o'Groats to Land's End to raise money for charity.

(21b)I propose that we (should) do the walk in the spring.

(21c)I propose that we (should) forget the whole thing.

Each of $(21 \mathrm{a}-\mathrm{c})$ could have a THAT or an ING complement. The ING alternative sounds fine in (21a), since it introduces the idea of a continuous activity. For (21b) a THAT construction is preferred - the walk is now being referred to as an 'event' and a time suggested for it. Sentence (21c) again refers to the walk as a 'unit'; the ING alternative to (21c), ${ }^{*}$ I propose (our) forgetting the whole idea, sounds particularly infelicitous.

This shows that no matter how close in meaning between the structures, there always exist differences in meaning and function as well between them.

Dixon (2016:241) also points out : There is another factor which motivates the choice between THATand ING complement clauses: only an ING construction allows the complement clause subject to be omitted when it is co referential with an appropriate main clause constituent. There is, in most styles of English, a preference to omit a repeated constituent and —all else being equal, or nearly equal_ an ING complement may be preferred to a THAT one for this reason. Thus, if I were the only person planning to walk the length of Britain, then I propose doing the walk in the spring might be preferred to I propose that I (should) do the walk in the spring. Or, consider regret, which can take a THAT or ING complement, as in:

(22a)I regret that they didn't walk out of that film when the violence started. 
(22b) I regret their not walking out of that film when the violence started.

Native speakers find (22a) and (22b) about equally acceptable. However, when the complement clause subject is co referential with main clause subject they exhibit a preference for the ING construction; I regret not walking out ... (although the latter is still considered grammatical).

As to the syntax and semantics of that clause following propose, we can get some enlightenment from several examples from Herbst (2004:622) : + (that)-CL（it）

BThe Report proposed that local authorities, together with the police, should be given a clear statutory responsibility for crime prevention in the area. He would also be proposing that they hold joint peace rallies in areas affected by violence. He did not propose she join him.

CJohn Locke proposed that the contents of all children's minds were essentially alike.

In the sentence B, propose means' suggest'; In sentence C, propose means' claim'.

Now let's see the use of be in that clause

Greenbaum (1996: 266) points out : Be is also used as the subjunctive of the progressive auxiliary [23] or passive auxiliary [24]:

(23) The technology of hard disk systems requires that the disk be spinning at about 3,000 revolutions per minute [...] [W2B-033-47]

(24) He proposed last June that American Medical be acquired by a new employee-stock ownership plan. [891012-0066-27]

The syntactic description of the different patterns following propose can be seen quite clear from the citation.

As to the differences of the two patterns, Dixon's(2016: 259)explanation is worth mentioning . He points out : Many verbs which take a Modal (FOR) TOcomplement also accept a THAT clause, and then the meaning of the Modal (FOR) TO construction is generally similar- though not identical- to a THAT construction where the complement clause includes a Modal.

When describing the use of that clause following propose et al, Greenbaum (1996:268) says: In British English the usual-and more common-alternative to the mandative present subjunctive is should with the infinitive, but the indicative is sometimes used.

However,there still exist some points to be further explained.

The pragmatic differences between these patterns are still not clearly explained. Comparatively speaking, Close's (1983:47) description is much better:

: ...Verbs like PROPOSE and RECOMMEND refer only to imagined action in the future, as

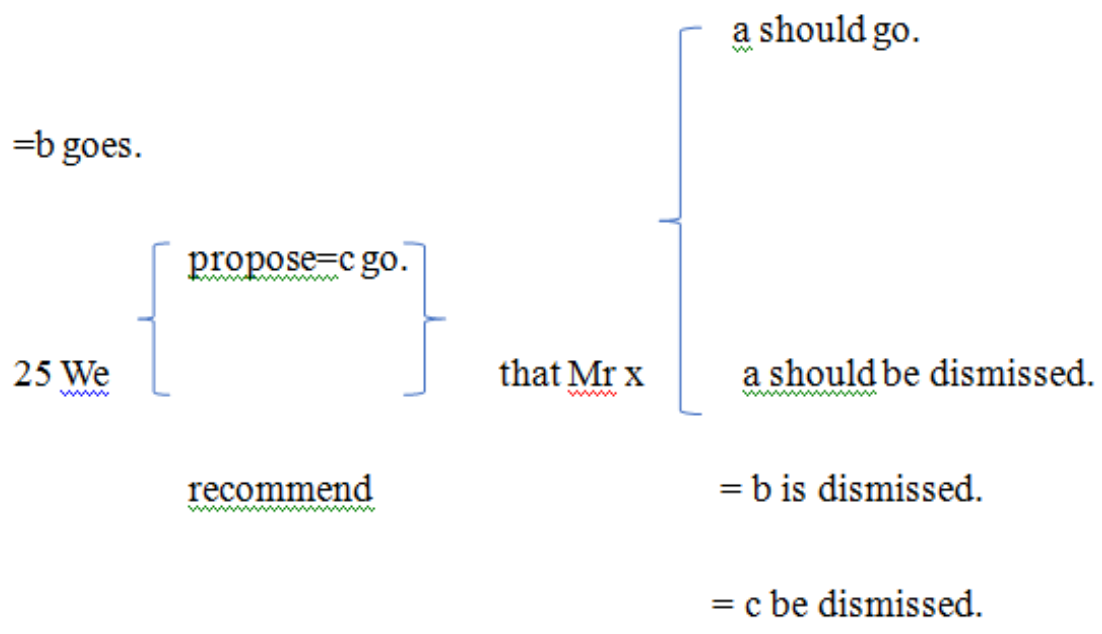

Of the three active (ie not passive) possibilities after ' $\mathrm{Mr} \mathrm{X}$ ', and of the three passive possibilities,(a) might be regarded as normal,(b) as informal and (c) formal and typical of official style, especially in 
American English. The (c) forms (go for 3rd person singular, and be dismissed) are traditionally called SUBJUNCTIVE.

After understanding the above explanation and analysis, it is not difficult to make an analysis of the semantic meaning of the following sentences and get a conclusion.

The New Sunrise English-ChineseDictionary(SONG \& CHEN 2001:1593)regard the following sentences are equal:He proposed(our) leaving now. $=$ He proposed to leave now. I proposed that we should take a trip to Hawaii. = I proposed (our)taking a trip to Hawaii.

We hold that the two pair of sentences are said to be equal by the authors. However it is only comparatively speaking. For example, that clause is always related with information or knowledge, whose pragmatic situation is different from that of infinitive and ing forms. In the translation from Chinese into English,even if we prepare to use a that clause, there is also a problem of making a choice of the language forms based on the context.( WU,2019:83)

\section{Proposal OR PROPOSITION?}

In the English-Chinese and Chinese- English translations, it is worth noting that the choice between proposal and proposition, the usage features of the two words. Comparatively speaking, the use of proposal is simpler, but it is easy for Chinese people to make mistakes. People should use propose to do something, and not proposal of doing something. See the examples from Longman Dictionary of Common Errors (Turton \& Heston, 1996:271):

(26)*The proposal of building a new motorway received little support.

(27)The proposal to build a new motorway received little support.

Proposal to do sth: 'The proposal to close the hospital was rejected.'

As to the interchangeability of the two words,Manser(2000:213), when describing the difference of the two words, points out: Both these nouns can mean 'Something that is proposed, suggested, or put forward for consideration', but they are not always interchangeable: the government's latest proposal/proposition That's an interesting proposition/proposal. An insurance proposal, a business proposition. The book points out clearly: these two words have other particular meanings and should not be confused:a proposal is an offer of marriage; a proposition is an invitation to extramarital sex. The verb proposition usually relates to this meaning of the noun(and is much more common than the noun in this sense): He propositioned his secretary ; it should not be used in place of propose.

Freeman (1990:214) points out : The proposal may be a good one, but not the choice of words. As a verb, proposition is informal, connoting something unseemly, perhaps illegal or immoral. It is best avoided. As a noun, proposition is used indifferently as a replacement for more suitable words, such as job, project, or proposal.

For thedifferences between the two words, Wilson (1993: 349) has his own opinions: Both are suggestions or offers of some sort, as in He made us a proposal [proposition] that I thought was very reasonable. Proposition like business, affair situation and concern, is used loosely to mean " a matter of some sort "or almost any "concern"or Vogue "thing": This Book like a tough proposition(whatever this may be).

In fact, this use of proposition exists for a long time.Mencken (2003:210)gives a description of proposition :The noun proposition began to take on wide and often preposterous significance in American during the 90's, and was soon in a lamentably swollen state.It meant a problem, proposal,person,parallel,premiss,postulate,parley,phenomenon, point,policy,philosophy,prospect,proce ss,petition,paradox or possibility, to mention only a few of its meanings under its own first letter.It went into English with the movies, and was denounced by H.W.Fowler in "Modern English Usage,"but it remained distinctively American there,and is now fading out of both languages, at least in its character of counter-word.

When describing proposition or proposal,Peter provides the reliable data for the frequency and context of the two words: Either of these could be used when it comes to a proposed plan or business offer. Yet the extra syllable and Latinate form of proposition makes it the more formal choice, and coincides with the fact that proposal is definitely the more common of the two, by a ratio of about 3:1 in the BNC.The more formal character of propositionhasbeen reinforced by its use in scholarly 
contexts, especially in mathematics and logic.Yet new idiomatic uses of proposition are increasing its popularity, witness a commercial proposition, an exciting proposition, a different proposition altogether. In phrases like those, applied to anything from the new motel,to a tempting holiday package, to the freshly signed-up football star,proposition becomes a faintly pretentious synonym for "prospect"or "venture." Proposal retains its basic link with the verb propose.

Nevertheless,proposal is definitely the more common of the two,by a ratio of about 2:1 in the Australian ACE databases. (Peter, 1996:616)

In 《A Concise Dictionary of Correct English》, Phythian(1982:116) says:

Proposition is a popular maid-of-all-work which is used to mean proposal (a business proposition), problem (a tough proposition), task (a stiff proposition), undertaking (a paying proposition), opponent (adifficultproposition), possibility (acommercialproposition), method (

anovelproposition) , etc.To use one word for so many purposes leads to slackness of expression; proposition deserves to be restricted to mean statement, assertion, and otherwise to be avoided in favour of more precise alternatives.

In 《The Right Word at the Right Time》, Kahn et al(1985:493) hold :The word proposition has various long-established senses - a suggested plan or business offer, a subject for discussion in a debate, a statement used in logical or mathematical analysis, and so on.It has, fairly recently, acquired two further senses that purists refuse to admit into Standard English.The first such sense is, roughly, 'any matter or person requiring special handling; any problem or prospect or enterprise or project or opponent or colleague considered abstractly':

(28)? Is that hotel a paying proposition, do you think?

(29)? Macleary, his right ankle still heavily bandaged, is a very doubtful proposition for the team's semi-final against Manchester on Saturday.

(30)? As an opening bowler,Holding is about as formidable a proposition as any batsman would care to face.

(31)? Don't think your viva voce exam is just a formality: it's known to be a tough proposition at times.

(32)? Social work will remain an unattractive proposition for job-hunters until the salary system is revised.

(33)?The kind of of guard dogs which the vet will no longer go near could be made a totally uneconomic proposition; they're in the position of man traps, which hurt without trial or argument, and which even the savage nineteenth century eventually banned.

\section{Katharine Whitehorn, The Observerists}

We hold that though the question markers are put at the beginning of the above sentences, it doesn't mean that these sentences are really not acceptable.The acceptance of such kind of sentences varies between linguists. The general tendency in pragmatics, however, is close to each other. For example, some dictionaries regard some of the uses as colloquial. See the three notes given by Wei(1985:377): 2. (colloq.) a project; undertaking: The business is a paying proposition. His store is a losing proposition. Family planning is an important proposition. 3. (colloq.) a problem: Building this skyscraper is a proposition. We have a talk on the proposition. The proposition is still pending. 4. (colloq) a person to be dealt with: The banker isaproposition.Fowler (1998:633) has also a special description: It is worth recording that Fowler (1926), writing at a time when the sense 'a matter of problem which requires attention (e.g. a tough proposition, an attractive proposition, a business proposition)' was widely felt In Britain to be an intrusive Americanism, sternly remarked, ' it is resorted to partly because it combines the charms of novelty and length, and partly because it ministers to laziness.' He wanted proposition to 'be bright back to its former well defined functions in Logic and Mathematics, and relieved of its new status as Jack-of -all-trades'. His advice,his admonitions, and his numerous illustrative examples (more than twenty, in contexts where, it was claimed, proposal, task, undertaking, possibility, prospect, enterprise,etc would have been more suitable) have all gone unheeded. 
Gilman(1994: 781) has a description providing enlightenment : Is the sensure of 1916-1927 still justified? Recent dictionaries-Webster'sThird, theOEDSupplement-do not stigmatize the term. You can judge its status for yourself from these early and recent examples:

(34)It looks like the biggest mining proposition on earth.

-Walter Church, quoted inN.Y. Evening Sun, 19 Mar. 1900

(35)This here sleeping proposition is a lottery--OwenWiserThe Virginian, 1902

(36)Now, it may occur to some that 33 different scientific bureaus under one head is rather a large proposition -CongressionalRecord, 26 Oct. 1921

(37)...finding ... the valley a most fat and satisfying proposition in the way of garden produce Mary Wiltshire, Thursday's Child, 1925

(38)But marriage is a very complicated proposition-U.S. Daily, 23 Aug. 1925

(39) He was absorbed in his own dexterity and in the proposition of trying to deceive a fish with a bird's feather and a bit of hair-JohnCheever, The Wapshot Chronicle, 1957

(40)The music hall is a worthless proposition economically--PaulGoldberger, N.Y.Times, 1 June 1979

(41)...getting a smile from her is a tough proposition-Barry McDermott, Sports Illustrated, 18 Jan 1972

(42)Punjabi is a much more solid proposition than Rajasthani and we take it as our second example- W.B. Lockwood, A Panorama of Indo-European Language, 1972

(43)The other book...is an altogether different proposition - Anatole Broyard, N.Y. Times Book Rev., 24 Mar. 1985

It is a normal phenomenon for the linguistic field to have different opinions on the use of proposition. Their very existence, however,is a fact without doubt. The context is worth noting.Just as Kahn et al point out:Proposition, used in this way, has become a vogue word, and illustrates the annoying tendency to abstraction found in so much modern speaking and writing.If used at all,it should be kept strictly for jocular or informal contexts.

The second new use of proposition, more commonly as a verb than a noun. To proposition a man or woman is to make an offer of sexual intercourse, often, though not necessarily, involving an exchange of money, and certainly not accompanied by a proposal of marriage! The word is well on its way to full acceptance, and can be found in police reports and court records, but it has still not quite crossed into standard idiom, and is once again best reserved for informal speech and writing.

Thus,it is clear that the use of proposal and proposition are not as easy as what normal lexical books introduces or explains. The exchange of the two words needs to satisfy some conditions and the use of each word is limited, especially when proposition is a noun whose meaning is changeable; used as a verb,there are quite a lot of limitations and also is easy to give rise to pragmatic failure. For those whose English is a second or foreign language, attention should be paid to the semantic meaning and pragmatic function of the two words .Propose has also many other semantic and pragmatic characteristics.Due to the limited space,they are not to be dealt with here in detail.

\section{CONCLUSION}

This paper has explored , and commented on, the commonly used word propose and its related items in the respects of syntax, semantics, and pragmatics in a multi- dimensional way, especially making a comparison between propose and suggest or put forward to in the potential meaning, usage feature and pragmatic function, uncovering the pragmatic motivation behind the choice of different structures.

Note: the asterisk $(*)$ is the sign to indicate an ungrammatical structure.

\section{REFERENCES}

[1] Atkinson, A. Macquarie Learners Dictionary [M]. NSW: The Mcquarie Library Pty Ltd, 1999.

[2] Borkin, A. Problems in Form and Function [M]. Norwood: Ablex Publishing Corporation, 1984.

[3] Bullon, S. Longman Exams Dictionary [M].Beijing: Foreign Language Teaching and Research Press, 2011. 
[4] Close, R. A. A Reference Grammar for Students of English[M]. Third impression. Longman Group Ltd. 1978.

[5] Egan, T. Non-finite Complementation[M]. Amster: Rodopi, 2008.

[6] Fowler, H. W. The New Fowler's Modern English Usage[M]. Revised third edition by H.W. Fowler. Oxford: Clarendon Press, 1998.

[7] Freeman, M. S. The Wordwatcher's Guide to Good Writing and Grammar [M]. Ohio: Morton S. Freeman, 1990.

[8] Fox, C.\& Combley, R. Longman Dictionary of Contemporary English, Fifth Edition,Pearson Education and Research Press.Foreign Language Teaching and Research Press, 2014.

[9] Gilman, E.W. Merriam -Webster's Dictionary of ENGLISH USAGE [M]. Springfield: MerrimackWebster, Incorporated, 1994.

[10] Greenbaum, S. The Oxford English Grammar [M]. Oxford: Oxford University Press, 1996.

[11] Herbs, T. et al. A Valency Dictionary of English [M].Berlin: Mouton de Gruyter, 2004.

[12] Kahn, J.E. The Right Word at the Right Time[M]. London: The Reader's Digest Association Limited, 1985. Langacker, R.W. Foundations of Cognitive Grammar: Descriptive applications [M].Berlin: Mouton de Grayter, 1991.

[13] Lea, D. Oxford Learner's Thesaurus [M]. Oxford: Oxford University Press, 2008.

[14] Manser, M. H .Bloomsbury Good Word Guide[M].London: Bloomsbury Publishing Plc,2000.

[15] Matsumoto, N, Bridges between Cognitive Linguistics and Second Language Pedagogy: The Case of Corpora and Their Potential [J]. SKY Journal of Linguistics , 2008,21 : 125-153.

[16] Mencken, H. L. The American Language [M]. New York: Alfred A. Knopf, Inc, 2003.

[17] Palmer, F. R. A Linguistic Study of the English Verb [M]. Miami: University of Miami Press, 1968.

[18] Peters, P. The Cambridge Australian English Style Guide [M]. Cambridge: CambridgeUniversity Press, 1996.

[19] Peters,P. The Cambridge Guide to English Usage [M]. Cambridge: Cambridge University Press,2004.9

[20] Phythian, B.A. AConciseDictionaryofCorrectEnglish[M]. Holder and Stoughton,Ltd. 1982.

[21] Randell, M. Longman Dictionary of English Language \& Culture(English-Chinese). The Commercial Press, 2004.

[22] Sinclair, J. Collins COBUILD English Usage[M].London: HarperCollins Publishes Ltd,1999.

[23] Sinclair, J. Collins COBUILD New Student's Dictionary[M]. Birmingham: HarperCollins Publishers, 1997

[24] SONG Meihua \&CHEN Chanbbgfang The New Sunrise English-Chinese Dictionary [M]. Beijing:SDX Sanlian Bookstore, 2001.

[25] Steel, M. Oxford Wordpower Dictionary for Learners of English [M]. Oxford: Oxford University Press. 2000.

[26] Swan, M. Practical English Usage[M]. Oxford: Oxford University Press, 1980.

[27] Thomson, A. J. \& Martinet, A. V. A Practical English Grammar [M]. Fourth Edition. Oxford: Oxford University Press, 1986.

[28] Turtleneck,N.D.\& Heaton,J.B. Longman Dictionary of Common Errors[M]. New Edition. Addison. Wesley Longman Limited, 1996.

[29] Verspoor, M. Semantic Criteria in English Complement Selection, Ph.D dissertation. University of Leiden, 1990.

[30] Walter, E. Cambridge Learner's Dictionary [M]. Cambridge: Cambridge University Press; Beijing: Foreign Language Teaching and Research Press, 2002.

[31] Wei, S. S. A Practical Dictionary of Business English (with Synonyms)[M]. Hong Kong: The Practical English Press, 1985.

[32] Wierzbicka, A English Speech Act Verbs [M]. NSW: Academic Press INC, 1987.

[33] Wierzbicka, A. The Semantics of Grammar [M]. Amsterdam: John Benjamin's Publishing Company, 1988.

[34] Wilson, K.G.The Columbia Guide to Standard American English [M]. New York: Columbia University Press, 1993.

[35] Wood, F. T. Gerund versus infinitive [J]. English Language Teaching, 1956, 11: 11-16.

[36] WU Guoliang. The Pragmatic Equivalence in the English-Chinese Translation from a FunctionalPerspective [J]. Shanghai Journal of Translators 2019(4).

[37] HUANG Guowen A Study on English Language [M].Guangzhou: Zhongshan University, 1999. 
[38] HUANG Guowen Theory and Practice of Discourse Analysis: A Study in Advertising Discourse [M]. Shanghai: Shanghai Foreign Language Education Press, 2001.

[Add】 : 428 Kuaiji Road, Yuecheng District, Shaoxing, Zhejiang, China

\section{AUTHOR'S BIOGRAPHY}

Dr. WU Guoliang, PhD, Professor of Zhejiang Yuexiu University of Foreign Languages, PhD Supervisor of Zhejiang University, Distinguished Visiting Professor of Arkansas State University, USA. His main interest includes Linguistics, Pragmatics, and translation. Address to No.428 Kuaiji Road, Yuecheng District, Shaoxing, Zhejiang 312000, China.

Citation:WU Guoliang. "The Choice of English Forms and Pragmatic Motivation----Taking Propose as an Example "International Journal on Studies in English Language and Literature (IJSELL), vol 8, no. 5, 2020, pp. 30-42. doi: http://dx.doi.org/10.20431/2347-3134.0805006.

Copyright:(C) 2020 Authors. This is an open-access article distributed under the terms of the Creative Commons Attribution License, which permits unrestricted use, distribution, and reproduction in any medium, provided the original author and source are credited. 